\title{
ARTICLE
}

Chronic lymphocytic leukemia

\section{CRISPR/Cas9-generated models uncover therapeutic vulnerabilities of del(11q) CLL cells to dual BCR and PARP inhibition}

\author{
Miguel Quijada-Álamo ${ }^{1,2} \cdot$ María Hernández-Sánchez ${ }^{1,2,3,4} \cdot$ Verónica Alonso-Pérez ${ }^{1,2}$. \\ Ana E. Rodríguez-Vicente $\mathbb{D}^{1,2} \cdot$ Ignacio García-Tuñón ${ }^{1,2} \cdot$ Marta Martín-Izquierdo ${ }^{1,2}$ • \\ Jesús María Hernández-Sánchez ${ }^{1,2}$ - Ana B. Herrero ${ }^{1,2}$ - José María Bastida ${ }^{2}$ Laura San Segundo ${ }^{1,2}$. \\ Michaela Gruber ${ }^{3,4,5,6}$. Juan Luis García ${ }^{1,2}$ - Shanye Yin $^{3,4}$ • Elisa ten Hacken ${ }^{3,4}$ - Rocío Benito ${ }^{1,2}$. \\ José Luis Ordóñez ${ }^{1,2} \cdot$ Catherine J. Wu $\mathbf{W}^{3,4}$ • Jesús María Hernández-Rivas ${ }^{1,2,7}$
}

Received: 18 October 2019 / Revised: 10 December 2019 / Accepted: 14 January 2020 / Published online: 23 January 2020

(c) The Author(s) 2020. This article is published with open access

\begin{abstract}
The deletion of 11q (del(11q)) invariably comprises ATM gene in chronic lymphocytic leukemia (CLL). Concomitant mutations in this gene in the remaining allele have been identified in 1/3 of CLL cases harboring del(11q), being the biallelic loss of ATM associated with adverse prognosis. Although the introduction of targeted BCR inhibition has significantly favored the outcomes of del(11q) patients, responses of patients harboring ATM functional loss through biallelic inactivation are unexplored, and the development of resistances to targeted therapies have been increasingly reported, urging the need to explore novel therapeutic approaches. Here, we generated isogenic CLL cell lines harboring del(11q) and ATM mutations through CRISPR/Cas9-based gene-editing. With these models, we uncovered a novel therapeutic vulnerability of del(11q)/ ATM-mutated cells to dual BCR and PARP inhibition. Ex vivo studies in the presence of stromal stimulation on 38 CLL primary samples confirmed a synergistic action of the combination of olaparib and ibrutinib in del(11q)/ATM-mutated CLL patients. In addition, we showed that ibrutinib produced a homologous recombination repair impairment through RAD51 dysregulation, finding a synergistic link of both drugs in the DNA damage repair pathway. Our data provide a preclinical rationale for the use of this combination in CLL patients with this high-risk cytogenetic abnormality.
\end{abstract}

These authors contributed equally: Miguel Quijada-Álamo, María Hernández-Sánchez

These authors jointly supervised this work: Catherine J. Wu, Jesús María Hernández-Rivas

Supplementary information The online version of this article (https:// doi.org/10.1038/s41375-020-0714-3) contains supplementary material, which is available to authorized users.

José Luis Ordóñez

jlog@usal.es

$\triangle$ Catherine J. Wu

cwu@partners.org

$\triangle$ Jesús María Hernández-Rivas

jmhr@usal.es

1 University of Salamanca, IBSAL, IBMCC, CSIC, Cancer Research Center, Salamanca, Spain

2 Department of Hematology, University Hospital of Salamanca,

\section{Introduction}

Deletion of chromosome 11q22.3 (del(11q)) can be found in up to $20 \%$ of chronic lymphocytic leukemia (CLL) patients at diagnosis and is associated with poor outcome [1-3]. Although the size of this deletion is variable [4-6], ATM is consistently deleted in most cases [6-8]. This gene, which plays a central role in double-strand break (DSB) signaling and repair [9], is mutated in 10-20\% of CLL cases

\section{Salamanca, Spain}

3 Department of Medical Oncology, Dana-Farber Cancer Institute, Boston, MA 02115, USA

4 Broad Institute of Harvard and MIT, Cambridge, MA 02142, USA

CeMM Research Center for Molecular Medicine, Vienna, Austria

6 Department of Internal Medicine I, Division of Hematology and Hemostaseology, Medical University of Vienna, Vienna, Austria

7 Department of Medicine, University of Salamanca, Salamanca, Spain 
at diagnosis [10-13]. One-third of CLL patients with del (11q) carry ATM mutations in the remaining allele, resulting in complete loss-of-function of the ATM protein [14] and significantly reducing the survival of these patients [15].

Novel agents targeting BCL2 and BCR signaling pathways have revolutionized the treatment landscape in CLL [16]. Specifically, it has been recently reported that treatment-naïve del(11q) CLL patients show durable responses upon first-line ibrutinib treatment [17] and an integrated analysis of long-term follow-up data from three randomized trials of ibrutinib in CLL revealed that ibrutinib-treated patients with del(11q) had a significantly longer progression-free survival than ibrutinib-treated patients without del(11q) [18]. However, responses to ibrutinib of high-risk patients harboring ATM functional loss through biallelic inactivation have not been explored yet. In addition, survival outcomes are inferior for relapsed/ refractory CLL patients, including those with del(11q) [19], and resistance to BTK inhibitors is becoming an increasing therapeutic challenge [20-24]. For these reasons, novel combinatorial therapies need to be explored in CLL patients.

One of the major impediments to the study of CLL biology has been the lack of cellular models faithfully representing the key genetic events of this disease, such as del(11q). While some studies have interrogated the biological impact of diverse individual CLL-associated genetic alterations [25-29], very few have analyzed the effects of concurrently expressed mutations in CLL [30]. Recently, Clustered Regularly Interspaced Short Palindromic Repeats (CRISPR)/Cas9 technology has allowed the efficient generation of mutations and chromosomal alterations in human cell lines and animal models, opening new approaches for modeling human diseases [31-34]. These new capabilities provide fresh opportunities to generate cell lines to mimic the concurrence of genetic alterations and to study specific therapeutic options.

In the present study, we used the CRISPR/Cas9 technology to generate stable isogenic CLL-derived cell lines harboring del(11q) and/or ATM mutations. The loss of ATM by del(11q) and gene mutation led to a defective doublestrand break (DSB) signaling resulting in increased genomic instability and hypersensitivity to the PARP inhibitor olaparib in vitro, in vivo and ex vivo. Furthermore, we showed that ibrutinib synergizes with PARP inhibition triggering synthetic lethality and significantly improving the effects of BCR inhibition as monotherapy in del(11q) cell lines and primary CLL cells. In addition, we demonstrated that the synergy mechanism between both is associated with the effect of ibrutinib in interfering with the homologous recombination repair through RAD51 downregulation. Our studies suggest that CRISPR/Cas9-generated models may provide powerful tools to study the effects of individual or combined CLL genetic alterations on cellular processes and treatment response.

\section{Methods}

\section{Study approval}

The ex vivo study was conducted in accordance of the Declaration of Helsinki and prior approval by the Bioethics Committee from our institution. Written informed consent was obtained from all patients. Animal studies were conducted in accordance with the Spanish and European Union guidelines for animal experimentation (RD53/2013, Directive-2010/63/UE, respectively) and received prior approval from the Bioethics Committee of our institution.

\section{Primary CLL samples}

Peripheral blood mononuclear cells (PBMCs) from 38 CLL patients were isolated using Ficoll-Paque Plus density gradient media (GE Healthcare, Life Sciences) and viably cryopreserved in liquid nitrogen until the time of analysis. A complete immunophenotypic analysis of all cases was carried out by flow cytometry. The main biological features of the CLL patients used in the study are summarized in Supplementary Table S1. Only CLL samples with CD19+/CD5+ purities greater than $85 \%$ were included.

\section{Next-generation sequencing (NGS)}

NGS results from the primary samples used in the ex vivo experiments are detailed in Supplementary Tables S2 and S3. Full details in Supplementary Information.

\section{CRISPR/Cas9-mediated mutagenesis in CLL cell lines}

HG3 and MEC1 cell lines (which harbor del(13q) and del (17p), respectively) were transduced with lentiviral particles containing plasmids for the constitutive Cas 9 expression (LentiCas9-Blast, Addgene_\#52692).

SgRNAs were designed using the online CRISPR design tool (http://crispr.mit.edu/) to target ATM. The selection of the sgRNAs was based on choosing those of highest efficiency to target the gene of interest and with the lowest predicted off-targets effects. For the generation of del(11q) on the HG3 cell line, two sgRNAs were designed targeting two $\sim 17 \mathrm{Mb}$ distal regions on chromosome 11 (11q22.1 and 11q23.3, respectively). In addition, a sgRNA designed not to target the human genome was used as a negative control. Sequences of the selected sgRNAs are detailed in Supplementary Table S4. SgRNAs targeting 11q23.3 were cloned into pLKO5.sgRNA.EFS.GFP (Addgene_\#57822) and 
sgRNAs targeting ATM and 11q22.1 into pLKO5.sgRNA. EFS.tRFP (Addgene_\#57823). Negative control sgRNA was cloned in both vectors. Cloning was carried out as previously described [35] and lentiviral transduction, nucleofection of 11q-targeting sgRNAs and clone screening are detailed below. At least three different clones harboring loss-of-function mutations were chosen for each CRISPRgenerated cell line to perform further functional studies. To mitigate against the possible biases due to off-targets effects of the sgRNAs, clones were generated using two different sgRNAs per gene.

\section{Ex vivo experiments}

Primary CLL ex vivo experiments were carried out in the presence of HS-5 bone marrow stromal cells as previously described [36]. Briefly, HS-5 stromal cells were seeded $24 \mathrm{~h}$ prior to the ex vivo study at a concentration of $1.5 \times 10^{4}$ cells/mL. On the following day, primary CLL cells were viably unfrozen and resuspended in RPMI 1640 medium (Life Technologies) supplemented with 10\% FBS, $1 \%$ penicillin/streptomycin and $1.5 \mu \mathrm{g} / \mathrm{mL}$ CpG ODN (SigmaAldrich) plus $50 \mathrm{ng} / \mathrm{mL}$ IL-2 (Peprotech) and subsequently seeded onto the HS-5 cell layer at a co-culture ratio of 100:1 $\left(1.5 \times 10^{6} \mathrm{CLL}\right.$ cells $\left./ \mathrm{mL}\right)$ to stimulate proliferation of CLL cells [37].

Cells were $\gamma$-irradiated ( $2 \mathrm{~Gy}$ ) $24 \mathrm{~h}$ after co-culture for $\gamma \mathrm{H} 2 \mathrm{AX}$ experiments. In the cell viability experiments, CLL cells in the co-culture condition were treated with the indicated drug doses on each experiment. After 120 h, CLL cells were detached from the stromal cell layer and viability was measured by CellTiter-Glo Luminescent Assay (Promega) and normalized with cells with no drug treatment.

\section{Statistics}

Statistical significance was determined using GraphPad Prism software v6 (GraphPad Software). Data are summarized as the mean \pm standard deviation (SD). Otherwise specified three independent clones per condition were used in the functional studies. Student's $t$ test, Mann-Whitney, ANOVA or Kruskal-Wallis tests were used to determine statistical significance. $P$ values lower than 0.05 were considered as statistically significant.

\section{Supplemental methods}

Supplemental Methods section include detailed protocols of cell lines and culture conditions, NGS, lentiviral production, cell transduction and nucleofection, PCR, FISH, flow cytometry, western blot, viability and apoptosis analyses, immunofluorescence, comet assay, transwell migration assay, homologous recombination (HR) activity assay and in vivo experiments.

\section{Results}

\section{Generation of del(11q) and ATM-deficient isogenic CLL-derived cell lines using the CRISPR/Cas9 system}

To address the biological implications of del(11q) and/or ATM mutations in CLL, HG3 and MEC1 CLL-derived cell lines were selected. Both are diploid for chromosome 11 and have wild-type (WT) ATM gene. Both cell lines were transduced with lentivirus expressing a constitutive Cas9 protein, generating HG3-Cas9 and MEC1-Cas9 cell lines with a Cas9 activity greater than $80 \%$ (Supplementary Fig. S1a, b).

For the generation of $\operatorname{del}(11 \mathrm{q})$, HG3-Cas9 cells were nucleofected with two sgRNAs targeting specific regions on chromosome 11q22.1 (sgRNA-A) and 11q23.3 (sgRNA-B), respectively. After single-cell sorting of $\mathrm{GFP}+\mathrm{RFP}+$ cells, clones were screened by PCR for the presence of a fusion region between $11 \mathrm{q} 22.1$ and 11q23.3 (Fig. 1a). Monoallelic del(11q) was present in $100 \%$ of the cells of the selected clone as validated by FISH (Fig. 1b), thereby establishing an isogenic HG3-del(11q) cell line. Truncating mutations of $A T M$ were introduced on the remaining WT allele of HG3-del(11q) cells (Fig. 1a). Single-cell FACSsorted clones were sequenced and the absence of ATM functional protein was assessed by western blot (Fig. 1c). In total, we generated three different clones of HG3-del(11q) and HG3-del(11q) $A T M^{\mathrm{KO}}$ conditions. A similar approach was used to generate single-cell clones with single ATM mutations in MEC1 and HG3 cell lines, validating the loss of ATM in three clones per condition (Fig. 1c; Supplementary Fig. S2a, b).

\section{Del(11q) $A T M^{\mathrm{KO}}$ cells show impaired double-strand breaks signaling, leading to DNA damage accumulation}

ATM is known to phosphorylate histone $\mathrm{H} 2 \mathrm{AX}$ in response to DSBs, promoting DSB repair [9]. To test how the CRISPR/ Cas9-engineered CLL cells respond to DSBs, $\gamma \mathrm{H} 2 \mathrm{AX}$ foci formation was investigated in the presence or absence of exposure to $\gamma$-irradiation (IR). By immunofluorescence, the number of foci was markedly lower in HG3-del(11q) clones than in $\mathrm{HG}^{\mathrm{WT}}$ cells following IR exposure $(P=0.004$; Fig. 2a). In addition, biallelic inactivation of $A T M$ dramatically reduced the number of foci formed after IR (Fig. 2a). These results were corroborated in $\mathrm{HG} 3$ and MEC1 $A T M^{\mathrm{KO}}$ cells (Supplementary Fig. S3a, b) as well as in del(11q)/ATMmutated primary CLL cells (Fig. 2b). 


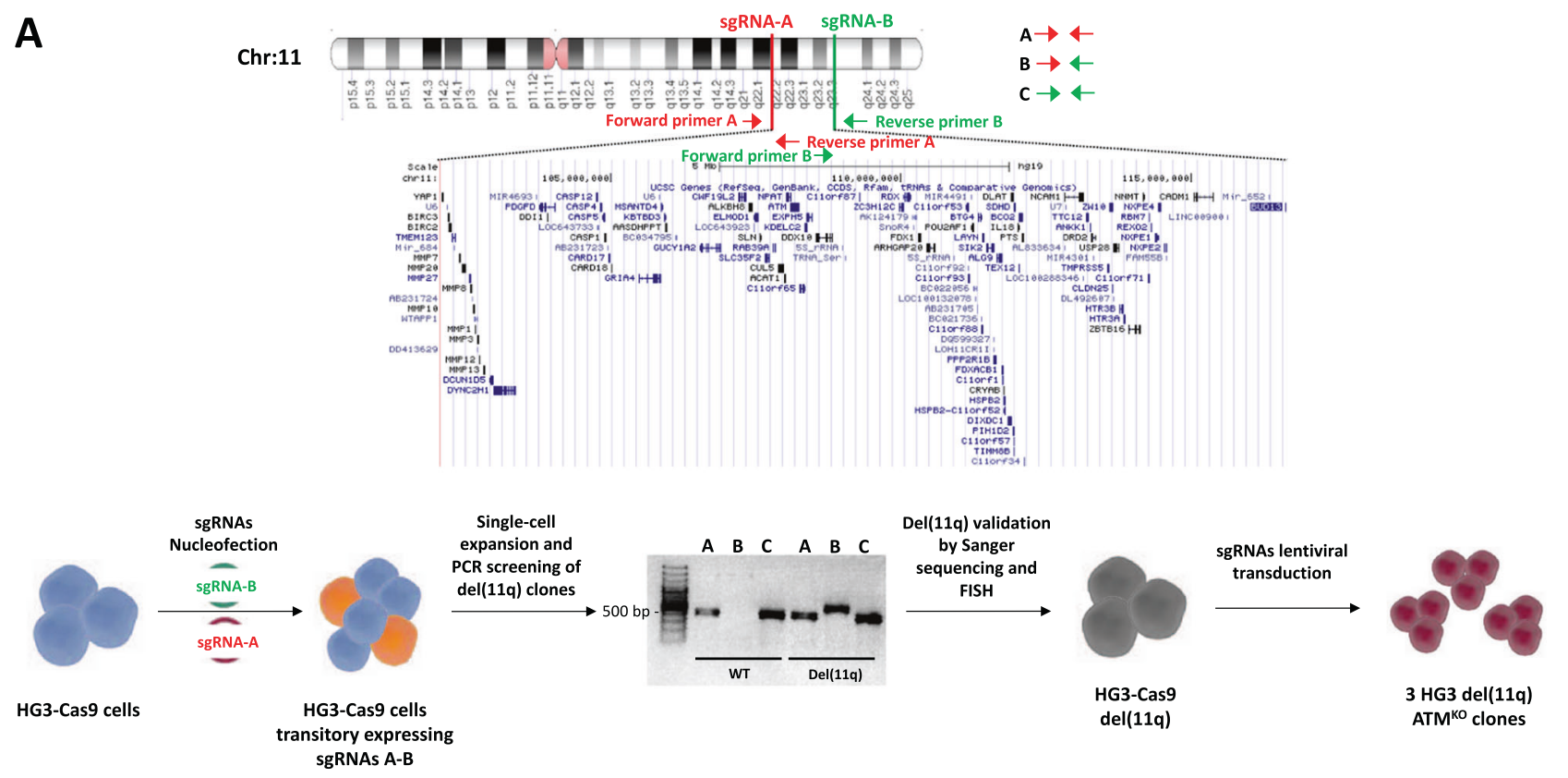

B

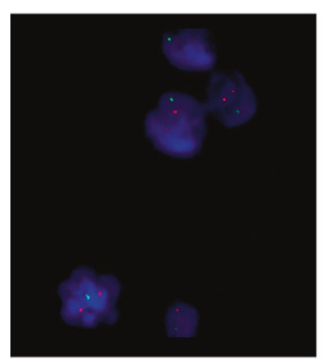

C

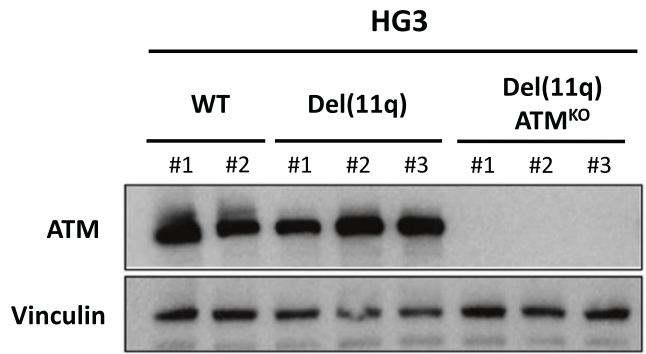

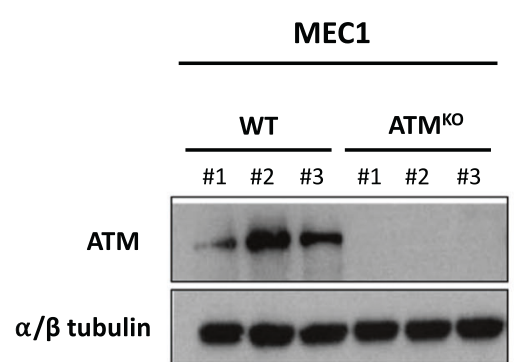

Fig. 1 Generation of 11q deletion and ATM mutations in CLL cell lines using the CRISPR/Cas9 system. a Upper panel presents the design of the generation of $11 \mathrm{q}$ deletion in HG3 cells and the genes contained within the two sgRNA-targeting sites (sgRNA-A in red, sgRNA-B in green). PCR primers used for detection of the deletion are indicated by arrows. Lower panel shows a diagram with the steps for the generation of an HG3-del(11q) cell line. Single-cell sorted clones transitory expressing sgRNAs A and B were screened for the presence of del(11q) by PCR reactions A, B and C, using two pairs of primers flanking upstream and downstream sgRNAs cut sites on chromosome 11. Only del(11q)-positive clones showed amplification using the

Since del(11q) cells displayed impaired DNA damage signaling, neutral comet assays were performed to elucidate whether these cells presented DSB accumulation after $\gamma$ irradiation. Notably, all the HG3 clones harboring del(11q) showed DNA damage accumulation $3 \mathrm{~h}$ after IR whereas $\mathrm{HG}^{\mathrm{WT}}$ cells were able to repair the DSBs (Fig. 2c). Furthermore, comet analyses revealed that the tail moment was higher in HG3 cells with biallelic inactivation of ATM than HG3-del(11q) cells with the remaining $A T M^{\mathrm{WT}}$ allele $(P<$ 0.0001 ; Fig. 2c). forward primer A (11q22.1) and the reverse primer B (11q23.3) (indicated as "PCR B"), as a result of a fusion product between both cut sites A and B. HG3-del(11q) isogenic cell line was subsequently used for the generation of $A T M$ mutations on the remaining wild-type allele of HG3-del(11q) cells. In total, $n=3$ HG3-del(11q) ATM ${ }^{\mathrm{KO}}$ clones were generated. b FISH analysis of HG3-del(11q) cell line. Green signals correspond to 11q22/ATM probe and the control red signals correspond to $17 \mathrm{p} 13 /$ TP53 probe. c Western blot analyses of HG3-del(11q) and MEC1 edited single-cell clones with ATM mutations ( $n=3$ clones per condition).

\section{CRISPR/Cas9-engineered del(11q)/ATM ${ }^{\mathrm{KO}} \mathrm{CLL}$ cells show high sensitivity to PARP inhibition in vitro and in vivo}

Considering that del(11q) and ATM mutations lead to defective DNA repair, we hypothesized that these cells could be hypersensitive to other drugs that also interfere the DNA repair pathways, such us PARP inhibitors [38]. To analyze this, HG3 clones were treated with olaparib. Of note, clones with biallelic inactivation of ATM due to del 

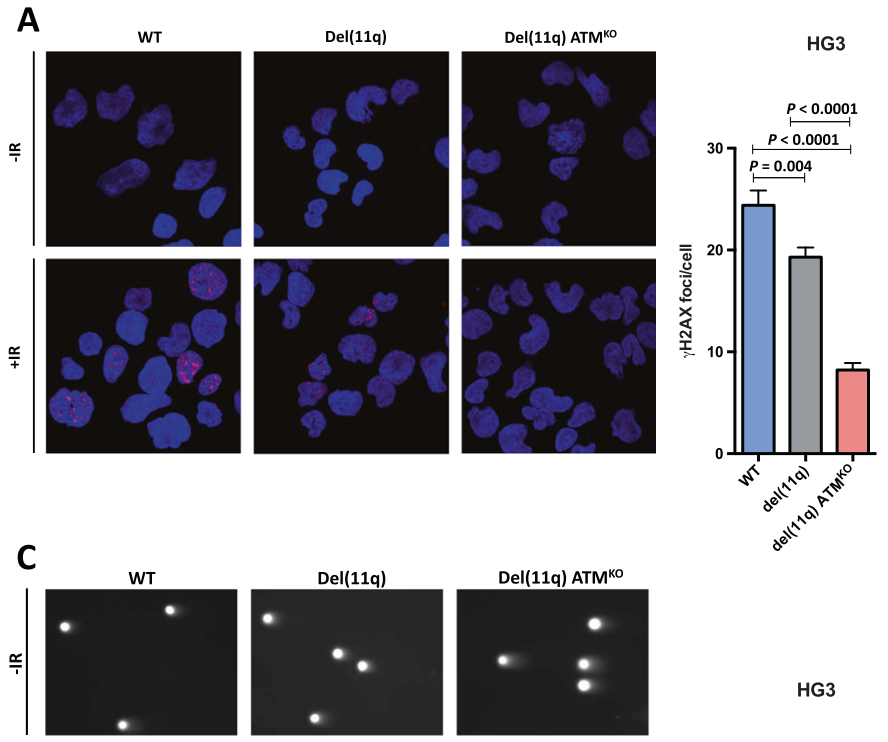

B
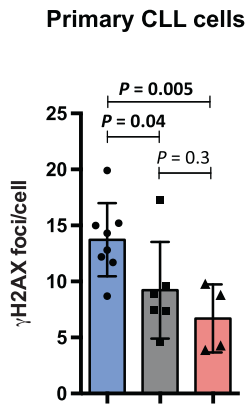

$\square \operatorname{ATM}^{W T}(n=8)$

$\square$ ATM monoallelic inactivation $(n=6)$ $\square$ ATM biallelic inactivation $(n=4)$
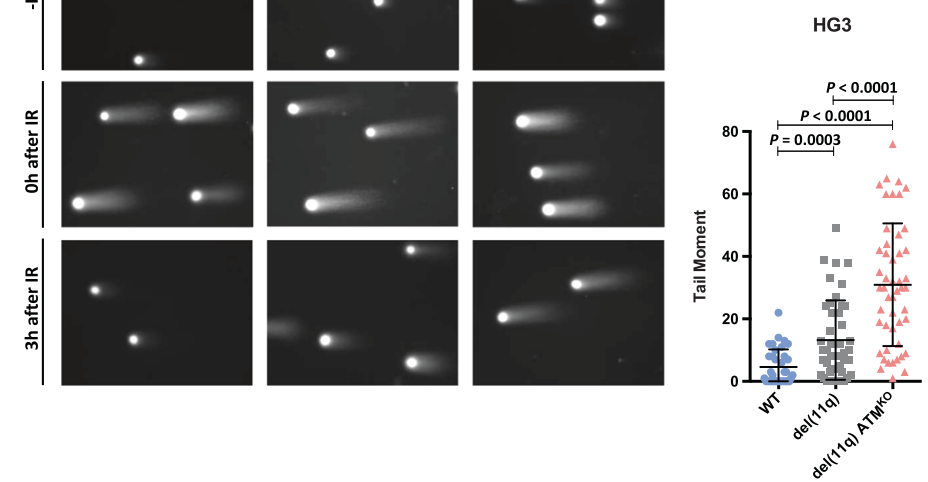

Fig. 2 Evaluation of double-strand breaks signaling and repair in del(11q)/ATM-deficient CLL cells. a Left panel: representative images of $\gamma \mathrm{H} 2 \mathrm{AX}$ foci formation (red) in $\mathrm{HG}^{\mathrm{WT}}$, HG3-del(11q) and HG3-del(11q) $A T M^{\mathrm{KO}}$ clones. Upper panel shows non-irradiated (-IR) HG3 cells and lower panel represents HG3 clones $1 \mathrm{~h}$ after 2 Gy irradiation $(+\mathrm{IR})$. Right panel: quantification of the number of $\gamma \mathrm{H} 2 \mathrm{AX}$ foci per cell $1 \mathrm{~h}$ after irradiation. Data are represented as the mean values \pm SD of three independent experiments. At least 75 cells per experiment were counted. b Quantification of the number of $\gamma \mathrm{H} 2 \mathrm{AX}$ foci per cell $1 \mathrm{~h}$ after irradiation in primary CLL samples stimulated to proliferate for $24 \mathrm{~h}$ before IR ( $2 \mathrm{~Gy})$. Groups are stratified based on $\operatorname{ATM}^{\mathrm{WT}}(n=8) \operatorname{ATM}$ monoallelic $(n=6)$ or biallelic $(n=4)$

(11q) and mutation on the other allele showed incipient sensitivity $72 \mathrm{~h}$ after treatment (Supplementary Fig. S4a). In addition, proliferation assays confirmed that del(11q) $A T M^{\mathrm{KO}}$ cells could not proliferate after olaparib treatment even after prolonged exposure (Fig. 3a). These results were also confirmed in MEC1 $A T M^{\mathrm{KO}}$ clones (Supplementary Fig. S4b).

To investigate the in vivo impact of olaparib treatment, $\mathrm{HG}^{\mathrm{WT}}(n=10)$ and HG3-del(11q) ATM $^{\mathrm{KO}} \quad(n=10)$ xenografts were generated in NSG mice. Olaparib or vehicle treatment started one week after cell injection (vehicle $n=4$; olaparib $n=6$ ) and hCD $45+\mathrm{GFP}+$ populations in the peripheral blood were monitored twice weekly. By FACS analysis, slower leukemic progression was observed in the $\operatorname{del}(11 \mathrm{q}) A T M^{\mathrm{KO}}$ mice treated with olaparib $(P=$ defects in CLL samples. At least 75 cells per patient were counted. Primary samples used in this experiment are detailed in Supplementary Table 1. c Left panel: representative images of the neutral comet assay experiment in $\mathrm{HG}^{\mathrm{WT}}$, HG3-del(11q) and $\mathrm{HG} 3-\mathrm{del}(11 \mathrm{q}) A^{\mathrm{W}} \mathrm{MO}^{\mathrm{KO}}$ clones. Upper images show non-irradiated HG3 comets, middle panel represents comets right after $40 \mathrm{~Gy}$ irradiation and lower images present comets $3 \mathrm{~h}$ after $40 \mathrm{~Gy}$ irradiation, when $\mathrm{HG} 3^{\mathrm{WT}}$ were able to repair the IR-generated DNA damage. Right panel: tail moment quantification of neutral comet assays in $\mathrm{HG}^{\mathrm{WT}}$, HG3-del(11q) and HG3-del(11q) $A T M^{\mathrm{KO}}$ clones $3 \mathrm{~h}$ after $40 \mathrm{~Gy}$ irradiation. Data represent the mean values \pm SD of at least 50 comets analyzed per condition in three independent experiments.

0.004 , at day 16 post-injection) whereas no differences were found between vehicle or olaparib treated WT xenografts (Supplementary Fig. S4c). Finally, overall survival was assessed at the end of the experiment, showing a significantly longer survival of $\operatorname{del}(11 \mathrm{q}) A T M^{\mathrm{KO}}$ xenografts treated with olaparib as compared with control $(P<0.01)$ (Fig. 3b).

\section{Ibrutinib has a synergistic effect with olaparib in vitro, enhancing its cytotoxic effects in del(11q) CLL cells}

To test whether the CRISPR/Cas9-engineered CLL cell lines could be used as models to pre-clinically test new therapeutic approaches, and given the promising effects of 
A

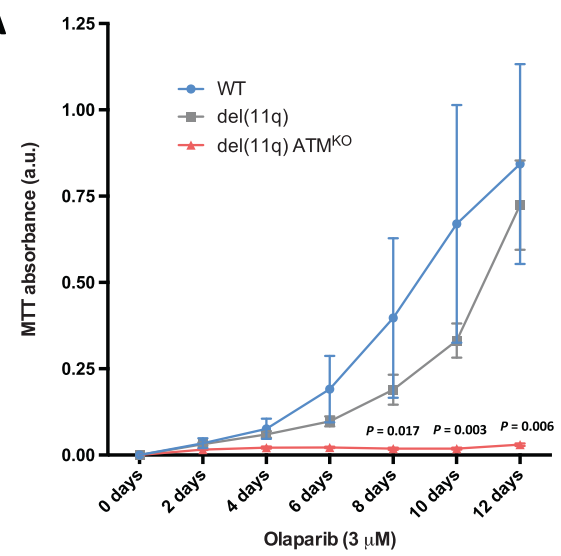

C

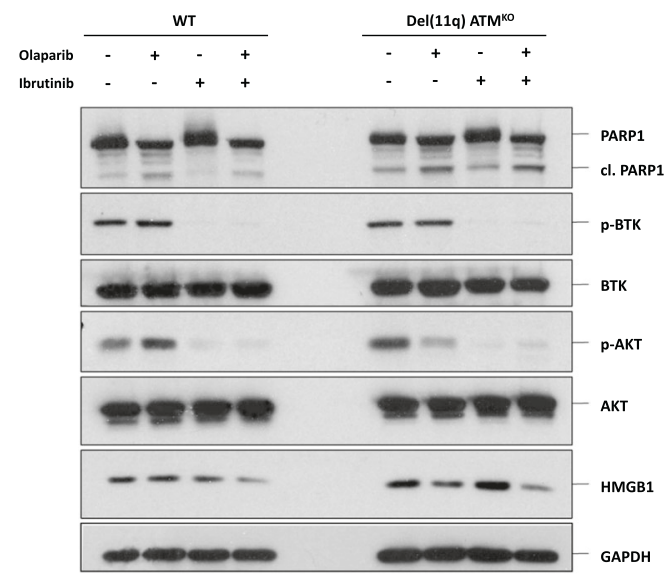

B
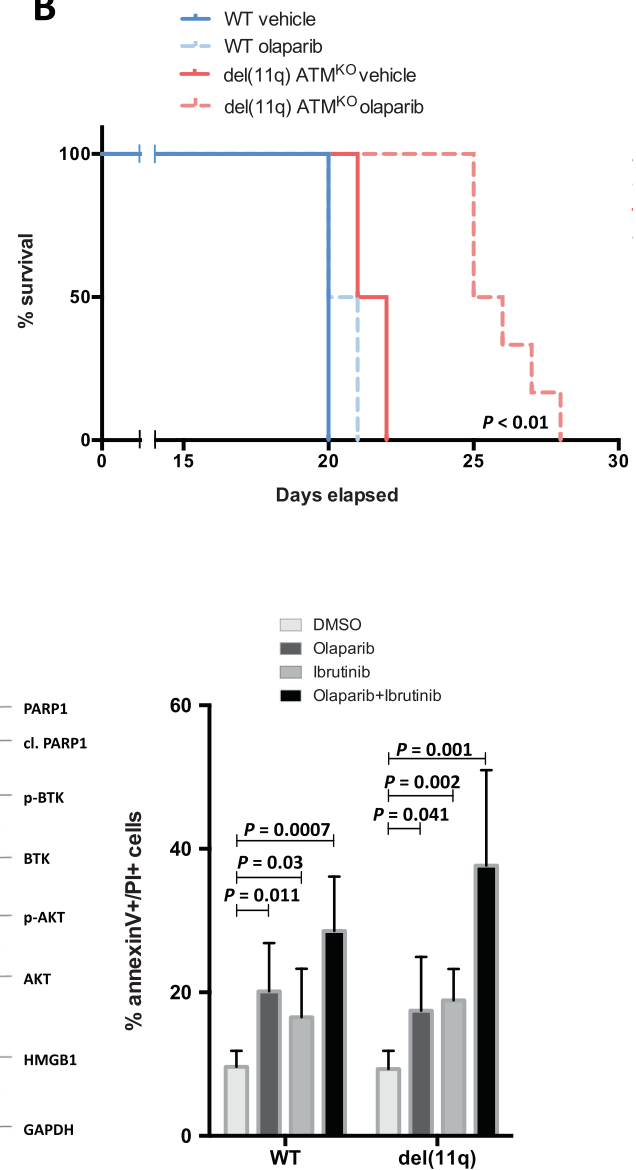

Fig. 3 Olaparib effects in CRISPR/Cas9-edited del(11q) cells in vitro, in vivo and in combination with ibrutinib. a HG3-edited clones were treated with $3 \mu \mathrm{M}$ olaparib and cell viability was assessed by MTT every 2 days up to 12 days. Proliferation rates are presented as MTT absorbance units, and data are shown as mean \pm SD. $P$ values indicate differences between $\mathrm{HG}^{\mathrm{WT}}$ and $\mathrm{HG} 3-\operatorname{del}(11 \mathrm{q}) \quad A T M^{\mathrm{KO}}$ clones. b Kaplan-Meier overall survival curve of $\mathrm{HG}^{\mathrm{WT}}(n=10)$ and HG3-del(11q) $A T M^{\mathrm{KO}}(n=10)$ xenografted mice treated with olaparib $(n=6)$ or vehicle $(n=4)$. The reported $P$ value was calculated by

olaparib on del(11q)/ATM-mutated CLL cells, synergy experiments were performed to test whether PARP inhibition could be combined with other drugs employed in CLL therapy. Strikingly, BCR inhibition by ibrutinib potentiated the effects of olaparib in cell viability in all the HG3-del (11q) and HG3-del(11q) ATM ${ }^{\mathrm{KO}}$ CRISPR/Cas9-generated clones and MEC1 cells (Supplementary Fig. S5a, b). Furthermore, olaparib also synergized with the alkylating agent bendamustine in all HG3-edited cell lines (Supplementary Fig. S5a). Responses of these isogenic HG3 cells to ibrutinib and bendamustine in monotherapy are depicted in Supplementary Fig. S5c.

We next focused on the combination of olaparib and ibrutinib due to its potential therapeutic application in del (11q)/ATM-mutated-relapsed/refractory CLL patients. As expected, the combination of these drugs induced
Log-rank test. c Left panel: immunoblot analysis of whole-cell lysates of $\mathrm{HG}^{\mathrm{WT}}$ and $\mathrm{HG} 3$-del(11q) $A T M^{\mathrm{KO}}$ cells exposed to $5 \mu \mathrm{M}$ olaparib and ibrutinib, either alone or in combination, after $48 \mathrm{~h}$. Right panel: cytotoxicity studies by annexin V/PI staining of HG3 ${ }^{\mathrm{WT}}$ and HG3-del (11q) cells treated with $5 \mu \mathrm{M}$ olaparib and ibrutinib for $48 \mathrm{~h}$. Cytotoxicity is measured as the percentage of PI + and annexin $\mathrm{V}+$ cells. Data are summarized as the mean $\pm \mathrm{SD}$ of four independent experiments.

PARP cleavage added to p-BTK and downstream p-AKT inhibition (Fig. 3c, left panel). In addition, ibrutinib synergistically enhanced olaparib cytotoxicity, leading to an incremented cell death, mostly by necrosis, as shown by annexin V and PI staining (Fig. 3c, right panel; Supplementary Fig. S5d, e). Moreover, necrosisdependent HMGB1 release [39] was studied in response to the drugs alone or in combination, finding a marked reduction of HMGB1 levels in $\mathrm{HG}^{\mathrm{WT}}$ and $\mathrm{HG} 3$-del(11q) $A T M^{\mathrm{KO}}$ cells exposed to the combination of olaparib and ibrutinib (Fig. 3c). Furthermore, we tested whether this combination affected the CCL19-mediated migration by chemotaxis assays, revealing that the drug combination at non-cytotoxic doses significantly reduced migration of CLL cell lines towards CCL19 (Supplementary Fig. S5f). 
Dual BCR and PARP inhibition is highly effective in del(11q)/ATM-mutated primary CLL samples in the presence of stromal stimulation

In order to validate whether these $\operatorname{del}(11 \mathrm{q}) / A T M$-mutated CRISPR/Cas9 models could be used as a predictive preclinical tool for the study of novel therapeutic approaches, we examined the effects of the combination of olaparib and ibrutinib ex vivo in primary cells from a cohort of 38 CLL samples (non-del(11q) $n=23$; $\operatorname{del}(11 \mathrm{q}) n=15$ ). Given that olaparib exerts its action during G2/M cell cycle phase, CLL primary cells were stimulated to proliferate in the presence of stromal cells, CpG and IL-2 [37]. Consistently, the combination of olaparib and ibrutinib in stimulated primary CLL cells was synergistic, and more effective in those cases with del(11q) (Fig. 4a). The tested drug doses did not affect the viability of the HS-5 stromal cells used in the co-culture with CLL cells (Supplemental Fig. S6a). Furthermore, stratifying these samples by ATM monoallelic or biallelic inactivation, we observed that CLL cells harboring ATM biallelic inactivation were even more sensitive to dual BCR and PARP inhibition (Fig. 4b).

Next, we sought to determine if other traditional prognostic factors would predict response to the combination of BCR and PARP inhibition. Regarding FISH cytogenetic alterations, we found that only del(11q) patients, and not del(13q), trisomy 12 or normal karyotype patients, had significantly higher ex vivo sensitivity to the drug combination (Fig. 4c). In addition, by stratifying the cohort regarding IGHV mutational status, we detected an improved response of IGHV unmutated patients when compared with those IGHV mutated (Fig. 4c), in line with previous results showing a higher sensitivity of unmutated CLLs to ibrutinib [40]. In order to evaluate which genetic maker could have a greater influence on drug response, we compared IGHV unmuted/ATM ${ }^{\mathrm{WT}}$ group versus cases with $A T M$ biallelic inactivation, showing that CLL patients with biallelic loss of ATM were more sensitive to the drug combination (Supplemental Fig. S6b). In addition, we dissected the response to dual BCR and PARP inhibition based on the mutational status of known CLL driver genes, demonstrating that only patients harboring ATM mutations significantly correlated with a greater sensitivity to the drug combination (Fig. 4c). Interestingly, SF3B1 mutations, which also play a role on the DNA damage response $[30,41]$, showed a trend towards higher sensitivity to the combination as well. On the other hand, TP53, NOTCH1 or XPO1 mutations did not have an influence on the response to the combination of olaparib and ibrutinib (Fig. 4c).
BCR inhibition impairs homologous recombination repair through RAD51 downregulation

Considering that olaparib and ibrutinib exert its action through different pathways, we hypothesized that the synergistic effects of this combination could be due to an off-target effect of ibrutinib in DNA damage repair. To determine if BTK inhibition affected the assembly of DNA repair foci on CLL cells, we investigated whether $\mathrm{HG}_{3}{ }^{\mathrm{WT}}$ and HG3-del(11q) $A T M^{\mathrm{KO}}$ cells were able to recruit RAD51 to DSBs after $\gamma$-irradiation in the presence of ibrutinib. Surprisingly, the formation of RAD51 foci $6 \mathrm{~h}$ after IR was significantly reduced in CLL cells treated with ibrutinib or the combination than in untreated cells (Fig. 5a, left panel). In addition, ibrutinib treatment reduced the protein levels of RAD51 in these clones (Supplementary Fig. S7a). Similar results were obtained in MEC1 cells treated with ibrutinib (Supplementary Fig. S7b). We further investigated these findings through the analysis of transcriptomic RNA-seq data of serial samples of CLL patients treated with ibrutinib [23], confirming that RAD51 RNA levels are significantly reduced in CLL patients after 1 month and 6 months of ibrutinib therapy (Fig. 5a, right panel).

Moreover, we determined whether this RAD51 downregulation after ibrutinib exposure could be related to the downstream PI3K/AKT/mTOR signaling modulation of BTK inhibition. To this extent, we first used the pan-specific PI3K inhibitior copanlisib in the CRISPR/Cas9-generated cells, showing that PI3K inhibition also reduced the recruitment of RAD51 to DSB lesions (Supplementary Fig. S7c), presenting synergistic effects with olaparib in stimulated primary CLL cells (Fig. 5b, left panel) and CLL cell lines (Supplementary Fig. S7d). In addition, the selective PI3K $\delta$ inhibitor idelalisib also showed synergism with olaparib in primary CLL cells (Fig. 5b, middle panel). In line with these results, the RAD51 inhibitor B02 also synergized with olaparib in stimulated CLL primary samples (Fig. 5b, right panel) and $\mathrm{HG}^{\mathrm{WT}}$ and $\mathrm{HG} 3-\operatorname{del}(11 \mathrm{q}) \quad A T M^{\mathrm{KO}}$ CRISPR/Cas9-edited cells (Supplementary Fig. S7d).

We next examined whether ibrutinib-mediated downregulation of RAD51 could reduce the homologous recombination (HR) repair activity of HG3 cells. Thus, we used an HR-reporter plasmid [42, 43] where GFP expression is restored upon HR repair (Fig. 5c). Consistently, ibrutinib treatment reduced the HR repair activity of HG3 cells at 1 and $2.5 \mu \mathrm{M}$ concentrations (Fig. $5 \mathrm{c}$ ).

\section{Ibrutinib enhances olaparib and bendamustine- dependent accumulation of DSBs in del(11q) cells}

Taking into account these results, it could be suggested that the mechanism of synergy of olaparib and ibrutinib in del 
A

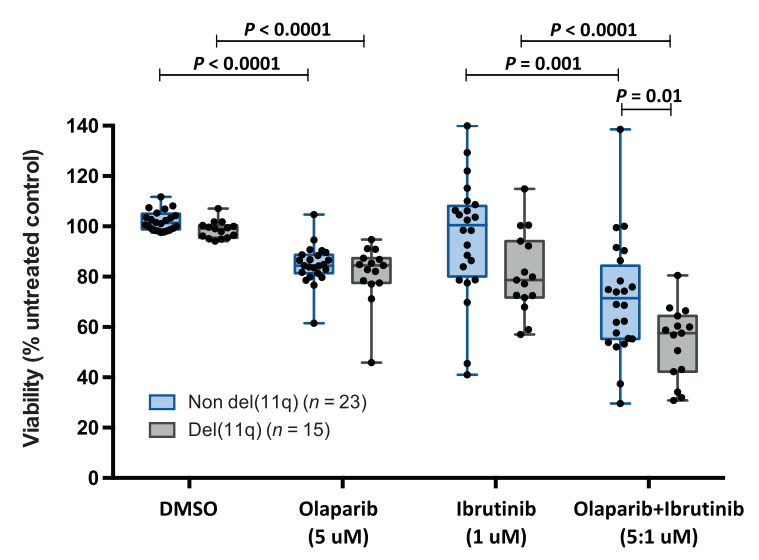

B
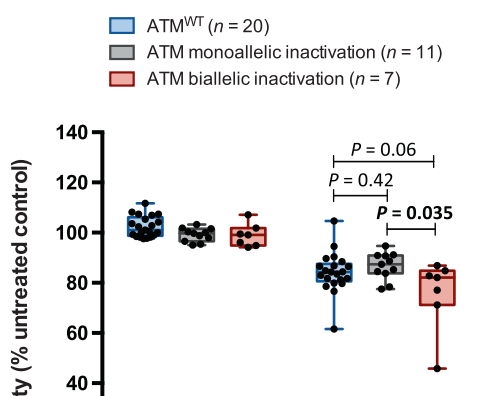
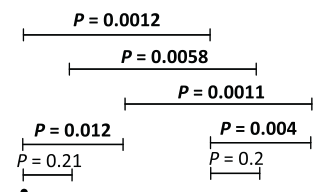
$P=0.21 \quad P=0.2$

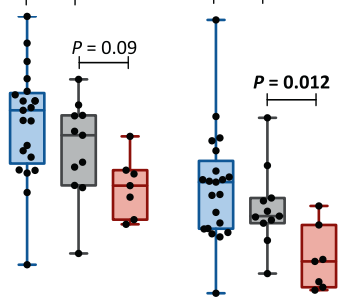

C
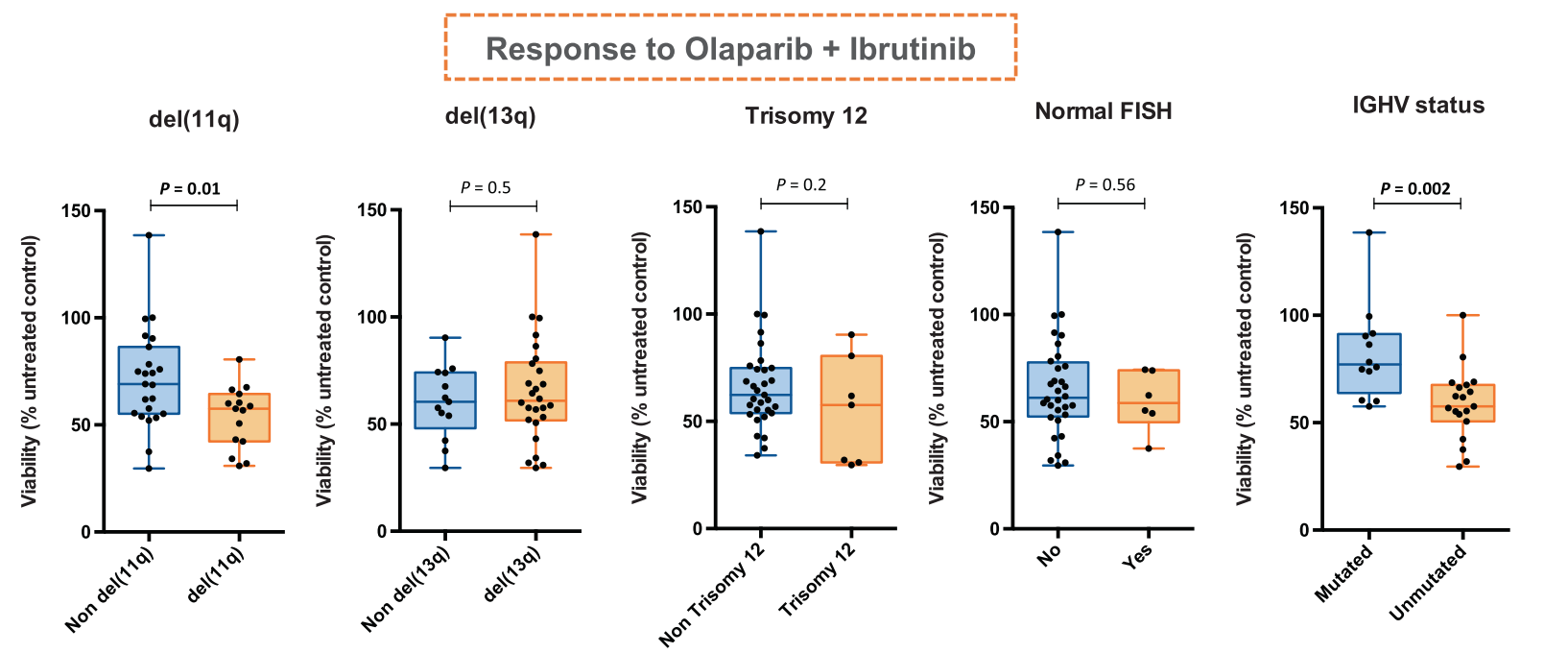

$\operatorname{del}(17 p) / T P 53$

ATM

SF3B1

NOTCH1
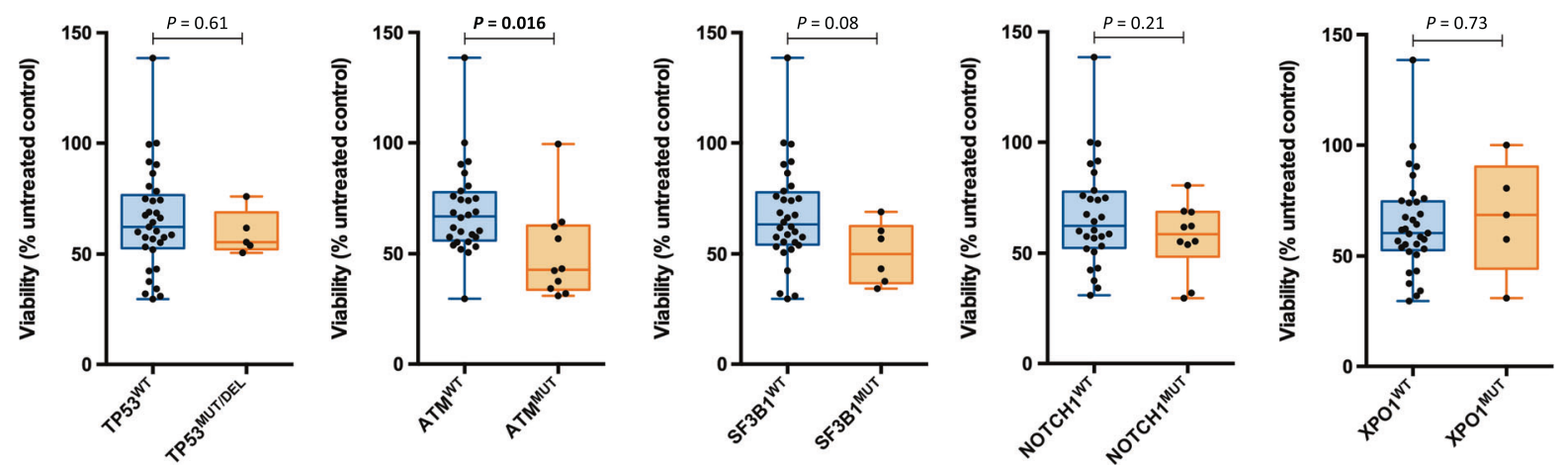

Fig. 4 Response to dual BCR and PARP inhibition of 38 CLL primary samples in the presence of stromal stimulation. a, b Primary CLL cells were seeded in co-culture with HS-5 bone marrow stromal cells, $1.5 \mu \mathrm{g} / \mathrm{mL} \mathrm{CpG}$ and $50 \mathrm{ng} / \mathrm{mL}$ IL-2 and treated with olaparib $(5 \mu \mathrm{M})$, ibrutinib $(1 \mu \mathrm{M})$ or the combination of both for 5 days. Normalized surviving fraction is expressed relative to untreated cells. Data are presented as the mean \pm SD of del(11q) $(n=15)$ vs. non $\operatorname{del}(11 \mathrm{q})(n=23)(\mathbf{a})$ or $A_{T M}^{\mathrm{WT}}(n=20) ; A T M$ monoallelic defective

( $n=11)$ and ATM biallelic defective $(n=7)$ CLL cases (b). c Response of primary CLL cells $(n=38)$ to the combination of olaparib $(5 \mu \mathrm{M})$ and ibrutinib $(1 \mu \mathrm{M})$ based on cytogenetics, IGHV mutational status and mutations in known CLL driver genes. Cells were seeded in co-culture with HS-5 bone marrow stromal cells, 1.5 $\mu \mathrm{g} / \mathrm{mL} \mathrm{CpG}$ and $50 \mathrm{ng} / \mathrm{mL} \mathrm{IL-2}$ and treated with the drug combination for 5 days. 


\section{A}
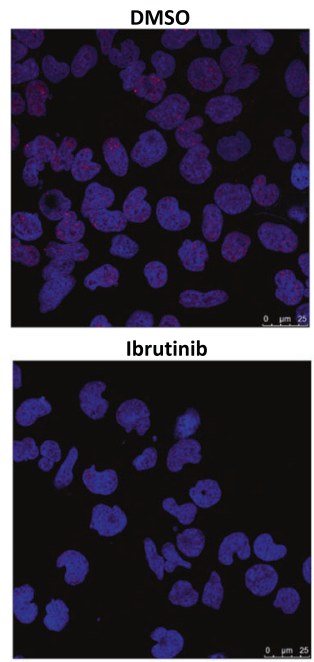

B
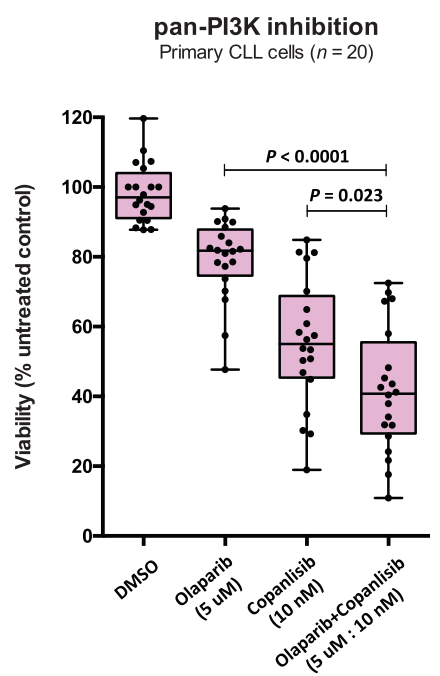

$\square$ DMSO

Olaparib

$\square$ Ibrutinib

Olaparib+lbrutinib

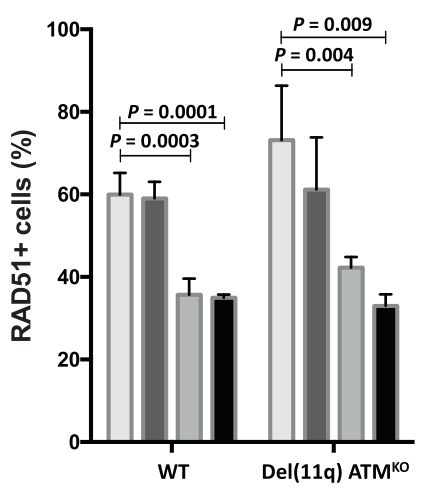

PI3K $\delta$ inhibition Primary CLL cells $(n=11)$

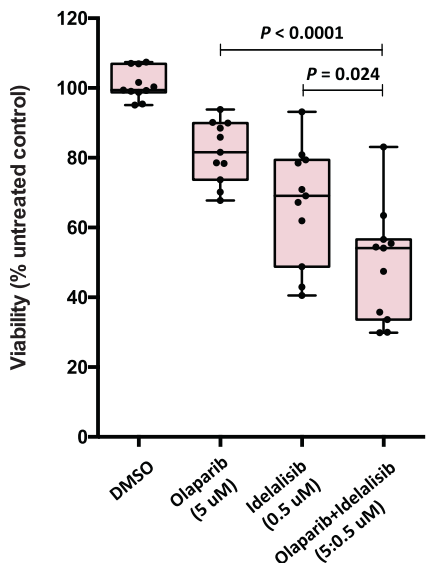

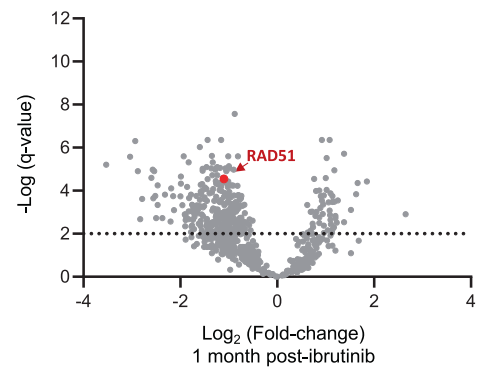

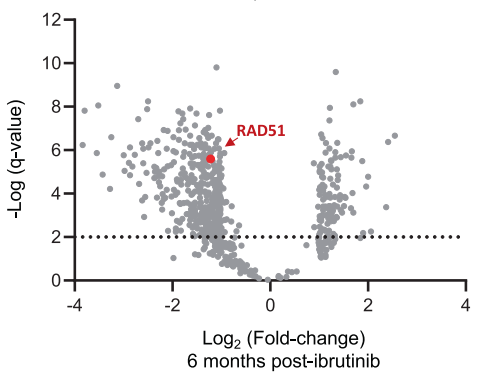

RAD51 inhibition

Primary CLL cells $(n=14)$

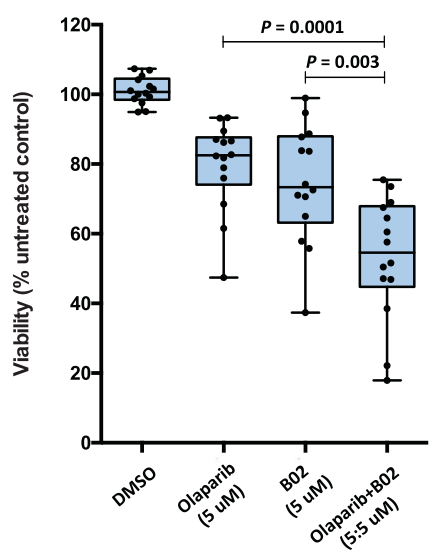

C
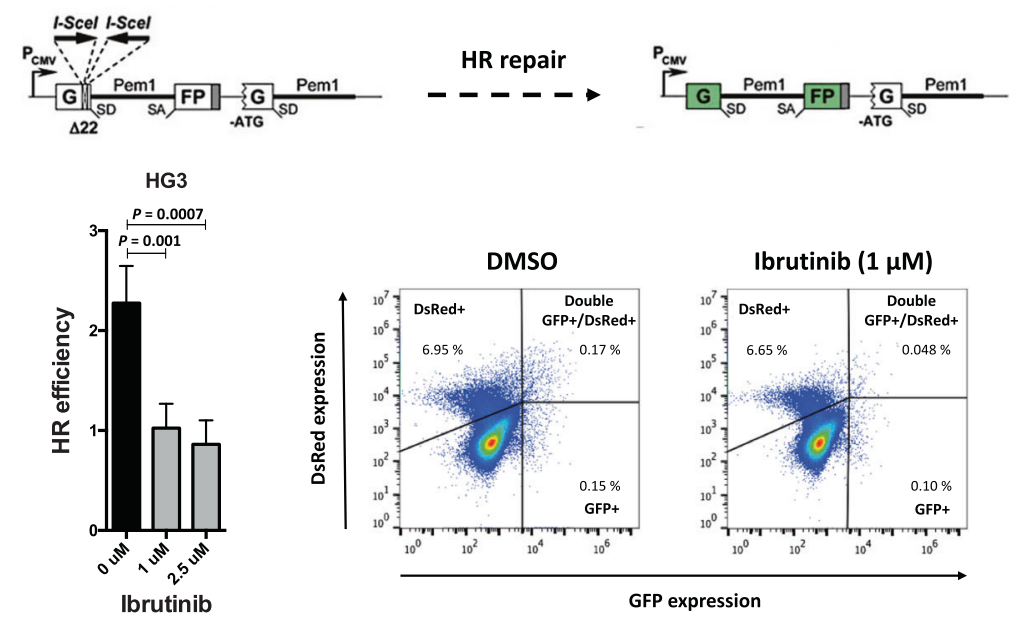

(11q) cells could be explained, at least in part, by synthetic lethality. Therefore, the addition of a DNA damage-inducing agent should increase the cytotoxicity of this combination due to large amounts of unrepaired DSBs. Interestingly, the addition of bendamustine to olaparib and ibrutinib synergistically reduced viability in all the HG3-del(11q) and 
Fig. 5 Effects of ibrutinib in RAD51-mediated HR repair in CLL. a Left panel: representative images and quantification of the number RAD51-positive cells $6 \mathrm{~h}$ after irradiation (2 Gy) in HG3 ${ }^{\text {WT }}$ and HG3$\operatorname{del}(11 \mathrm{q}) A T M^{\mathrm{KO}}$ clones. Cells were pretreated for $24 \mathrm{~h}$ with $5 \mu \mathrm{M}$ olaparib, $1 \mu \mathrm{M}$ ibrutinib or the drug combination. Data are represented as the mean values $\pm \mathrm{SD}$ of three independent experiments. Cells were scored RAD51 + when five or more foci were formed. At least 100 cells per experiment were counted. Right panel: volcano plots of transcripts changes comparing 1- (top) and 6-month (bottom) postibrutinib initiation vs. pretreated longitudinal samples in 14 CLL patients. $R A D 51$ expression is significantly downregulated in samples after 1 month and 6 months of ibrutinib therapy. $\log _{2}$ of fold-changes (treatment vs. control) are shown in $x$ axis and statistical significance ( $\log _{10}$ of $q$ value) is shown in $y$ axis. RNA-seq data were previously generated in Landau et al. [23]. b Primary CLL cells were seeded in co-culture with HS-5 bone marrow stromal cells, $1.5 \mu \mathrm{g} / \mathrm{mL} \mathrm{CpG}$ and $50 \mathrm{ng} / \mathrm{mL}$ IL-2 and treated with the indicated drugs and doses for 5 days. Normalized surviving fraction is expressed relative to untreated cells. Data are presented as the mean \pm SD. c Upper panel displays a representation of the HR-reporter plasmid adapted from Seluanov et al. [43]. Lower-left panel represents the HR repair efficiency as calculated by dividing the number of GFP + cells of the totality of positivetransfected DsRed + cells. Data represent mean \pm SD of three independent experiments. Right panel displays representative plots of the HR efficiency of HG3 treated with DMSO or ibrutinib $(1 \mu \mathrm{M})$.

MEC1 $A T M^{\text {KO }}$ CRISPR/Cas9-edited clones (Fig. 6a; Supplementary Fig. S8a). In addition, the combination of the three of these drugs also resulted in decreased viability in a subset of stimulated CLL primary cells (Fig. 6b).

To validate that this reduction in cell viability was due to the accumulation of lethal DSBs, neutral comet assays were performed on $\mathrm{HG}^{\mathrm{WT}}$ and $\mathrm{HG} 3$-del(11q) $A T M^{\mathrm{KO}}$ cells after treatment with olaparib, ibrutinib and/or bendamustine. Remarkably, the triple combination of olaparib, ibrutinib and bendamustine led to larger amounts of unrepaired DSBs (Fig. 6c, Supplementary Fig. 8b). Of note, the dual combinations of olaparib + ibrutinib or ibrutinib + bendamustine induced higher levels of DNA damage than these drugs in monotherapy, supporting the aforementioned ibrutinibmediated impairment of HR repair. In addition, HG3-del (11q) $A T M^{\mathrm{KO}}$ cells exhibited more DNA damage upon olaparib + ibrutinib and the triple combination than $\mathrm{HG}^{\mathrm{WT}}$ cells, providing further evidence of the selective hypersensitivity of $\operatorname{del}(11 \mathrm{q}) / A T M^{\mathrm{KO}} \mathrm{CLL}$ cells to PARP inhibitors in combination with ibrutinib.

\section{Discussion}

The advent of next-generation sequencing has made feasible to unveil CLL as a highly genetically heterogeneous disease $[12,13]$. Specifically, del(11q) patients represent a heterogeneous group inclusive of individuals carrying bi-allelic inactivation of $A T M[6,14,15]$. The absence of cellular models harboring this deletion and the difficulty of collecting large cohorts of patients harboring all the possible combinations of del(11q) and/or ATM truncating mutations, have left remaining questions about the biological effects and treatment response related to these genomic alterations. In this study, we explored the implementation of the CRISPR/Cas9 technology to generate in vitro CLL models carrying del(11q) and/or ATM mutations. In this fashion, we generated unique isogenic cell lines mimicking the ATMrelated genomic heterogeneity seen in CLL patients.

Considering the genetic intratumoral heterogeneity underlying CLL patients, we have generated del[11q)/ATMmutated models in two different cytogenetic backgrounds (del(13q) in HG3 and del(17p) in MEC1). In addition, multiple driver mutations can co-occur within the same tumoral clone, usually driving clonal expansion of CLL cells $[44,45]$. Therefore, it is important to study how genetic alterations could synergistically act within the same tumor cell. To this extent, our CRISPR/Cas9 model is the first of its kind analyzing the biological impact of concurrent del(11q) and ATM mutations.

Our data show that these models faithfully represent the biology of ATM loss in the pathogenesis of CLL. In this way, the response of our CRISPR/Cas9-generated isogenic cell models to $\gamma$-irradiation was analyzed, showing that biallelic loss of ATM strongly impaired $\gamma \mathrm{H} 2 \mathrm{AX}$ foci formation after irradiation [46], leading to the accumulation of unrepaired DSBs. Interestingly, del(11q) CLL cells also showed moderate levels of unrepaired DNA damage after irradiation and biallelic ATM inactivation lead to higher levels of unrepaired DNA damage. Of note, del(11q) CLL patients displayed a higher rate of genomic alterations than patients without del(11q) [47, 48]. Therefore, our results suggest that the presence of del(11q) together with ATM mutations may be able to increase the risk of developing secondary genetic abnormalities in CLL cells, contributing to the appearance of subclonal genomic alterations frequently observed in CLL patients during the disease course and associated with poor outcomes [12, 44, 49].

Ibrutinib-mediated BCR inhibition has transformed the treatment landscape of CLL. Despite its proved benefits, disease progression on ibrutinib is being increasingly reported and ibrutinib resistance has emerged as a therapeutic challenge [20-24]. In addition, complex karyotype, which is associated with del(11q) [50], has been associated with poor outcome in ibrutinib-treated patients [51]. Therefore, novel therapeutic approaches need to be explored in high-risk CLL patients. Some studies have shown the efficacy of PARP inhibitors in ATM-deficient cell lines and murine models, respectively, but not in isogenic del(11q) models or large cohorts of genetically-matched CLL samples [52, 53]. The application of PARP inhibition to our CLL models has highlighted the efficacy of this drug in del(11q) cells with biallelic inactivation of ATM in vitro, in vivo and ex vivo. Remarkably, olaparib was especially effective in CLL cells with complete dysfunctional ATM 
A
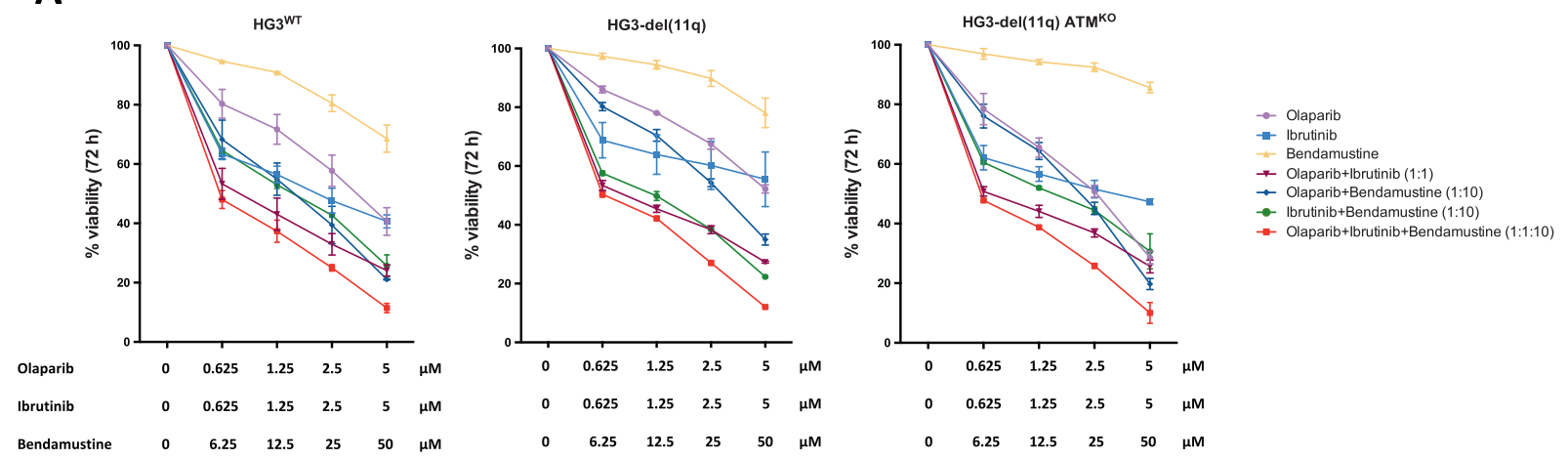

B

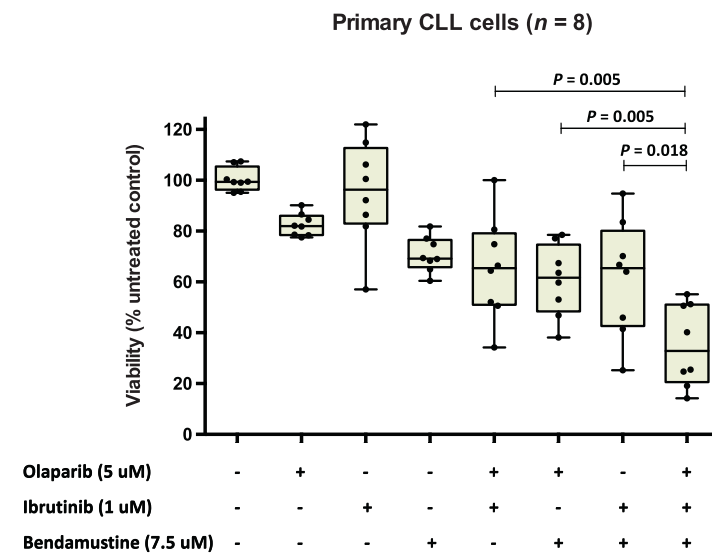

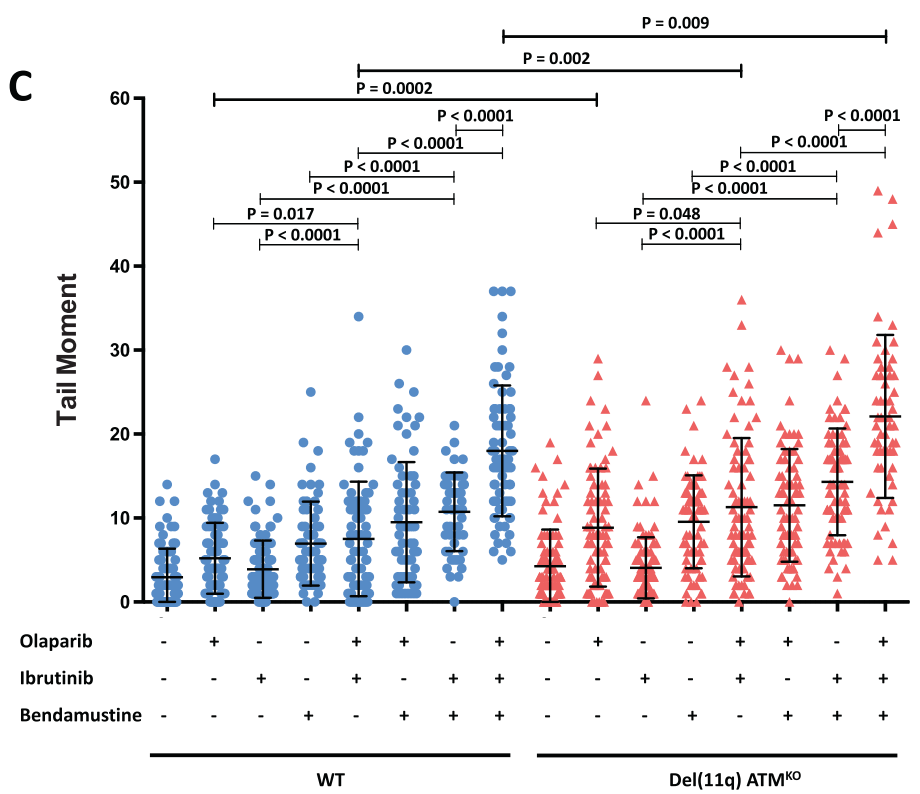

treated with the indicated doses of olaparib, ibrutinib and/or bendamustine for 5 days. Normalized surviving fraction is expressed relative to untreated cells. c Tail moment quantification of neutral comet assays in $\mathrm{HG}^{\mathrm{WT}}$ (blue) and HG3-del(11q) $A T M^{\mathrm{KO}}$ (red) clones $16 \mathrm{~h}$ after olaparib $(5 \mu \mathrm{M})$, ibrutinib $(5 \mu \mathrm{M})$ and/or bendamustine $(50 \mu \mathrm{M})$. Data are shown as the mean values \pm SD of at least 50 comets analyzed per condition in three independent experiments.

both drugs could be effective for del(11q)-relapsed/refractory CLL patients. Furthermore, our study suggests that the synergy mechanism could be due to a PI3K signalingdependent off-target effect of ibrutinib on HR repair through downregulation of RAD51, triggering synthetic lethality when combined with PARP inhibitors. Interestingly, combined PI3K and PARP inhibition have also provided more efficient responses in BRCA1-deficient breast cancer cells [55] and dual ATR and BCR inhibition has also been proven to be synergistic in ATM-defective CLL cells [56]. Moreover, it has been reported that BCR inhibitors could increase genomic instability in B cells [57] and transcriptomic data also support the evidence of RAD51 downregulation in CLL patients treated with ibrutinib (Fig. 5a) [23]. In fact, since the in $\operatorname{del}(11 \mathrm{q}) / A T M$-mutated CLL cells, the combination of 
addition of ibrutinib to bendamustine plus rituximab can significantly improve outcomes of CLL patients [58] and PARP inhibitors have been proven to be highly effective in HR-impaired breast and ovarian cancer patients [59, 60], relapsed/refractory $\operatorname{del}(11 \mathrm{q}) / A T M$-mutated CLL patients may potentially benefit from this combinatorial strategy.

Altogether, our results highlight that the CRISPR/ Cas9 system is an applicable technique for the generation of in vitro CLL models mimicking specific genomic alterations frequently observed in CLL patients. By using these models, we have delved into the knowledge on the effects of monoallelic del(11q) or biallelic ATM loss on the DNA damage response signaling in CLL. Furthermore, this work demonstrates that PARP inhibition in combination with ibrutinib may be explored as a therapeutic option for del (11q) CLL patients showing ATM biallelic inactivation.

Acknowledgements This work was supported by grants from the Spanish Fondo de Investigaciones Sanitarias PI15/01471, PI18/ 01500, Instituto de Salud Carlos III (ISCIII), European Regional Development Fund (ERDF) "Una manera de hacer Europa", "Consejería de Educación, Junta de Castilla y León" (SA271P18), "Proyectos de Investigación del SACYL", Spain GRS 1847/A/18, GRS1653/A17,"Fundación Memoria Don Samuel Solórzano Barruso" (FS/23-2018), by grants (RD12/0036/0069) from Red Temática de Investigación Cooperativa en Cáncer (RTICC), Centro de Investigación Biomédica en Red de Cáncer (CIBERONC CB16/12/00233) and SYNtherapy "Synthetic Lethality for Personalized Therapy-based Stratification In Acute Leukemia" (ERAPERMED2018-275); ISCIII (AC18/00093). MQÁ is fully supported by an "Ayuda predoctoral de la Junta de Castilla y León" by the Fondo Social Europeo (JCYL-EDU/ 529/2017 $\mathrm{PhD}$ scholarship); MHS was supported by a grant from FEHH/Janssen ("Sociedad Española de Hematología y Hemoterapia") and now holds a Sara Borrell postdoctoral contract (CD19/00222) from Instituto de Salud Carlos III (ISCIII), co-funded by Fondo Social Europeo (FSE) "El Fondo Social Europeo invierte en tu futuro"; AERV is supported with a research grant by FEHH ("Fundación Española de Hematología y Hemoterapia"); MG is supported by a Marie Curie Action International Outgoing Fellowship (PIOF-2013-624924); EtH is a Special Fellow of the Leukemia and Lymphoma Society (LLS) and a Scholar of the American Society of Hematology (ASH) and JLO is supported by a grant from the University of Salamanca ("Contrato postdoctoral programa II"). We thank Almudena Martín-Martín, Sara González, Irene Rodríguez, Teresa Prieto, $\mathrm{M}^{\mathrm{a}}$ Ángeles Ramos, Filomena Corral, $\mathrm{M}^{\mathrm{a}}$ Almudena Martín, Ana Díaz, Ana Simón, María del Pozo, Isabel M Isidro, Vanesa Gutiérrez, Sandra Pujante, Ma Ángeles Hernández, Sandra Santos and Cristina Miguel from the Cancer Research Center of Salamanca, Spain, for their technical support. We are grateful to Ángel Prieto, Ana I García and Sara Armenteros, María Luz Sánchez and María Carmen Macías from the Microscopy Unit, Cytometry Unit and Molecular Pathology Unit, respectively, from the Cancer Research Center of Salamanca for their technical assistance. We thank Javier Borrajo from the Service of NUCLEUS, University of Salamanca for his help with the irradiation experiments and Luis Muñoz and all the members from the Animal Experimentation Research Center from the University of Salamanca. We also thank Dr Gorbunova for the HR-reporter plasmid. We also want to thank Noelia Purroy and Romain Guièze from Wu's lab (Dana-Farber Cancer Institute, Boston) for their helpful suggestions about ex vivo experiments and CRISPR/Cas9-edited models, respectively. We are deeply grateful to Teresa González, José Ramón González Porras, Josefina
Galende, José Antonio Queizán, Carlos Aguilar and María Jesús Vidal Manceñido for providing patient samples and clinical information.

Author contributions MQÁ designed the experiments, performed CRISPR/Cas9 generation of $\mathrm{KO}$ cell lines, carried out functional studies, analyzed the data and wrote the paper, MHS designed the experiments, contributed to interpret the results and wrote the paper, VAP performed CRISPR/Cas9 generation of KO cell lines and functional studies, AERV performed functional studies and together with IGT contributed to the experiment design and data analyses, MMI and JMHS performed NGS studies, ABH designed DNA damage and repair experiments and contributed to data analysis, JMB provided primary samples for the ex vivo studies, LSS contributed in the xenograft experiments, MG contributed to the CRISPR system design, JLG performed functional studies, SY performed RNA-seq data analysis, EtH and RB contributed to data analyses, interpretation of the results and critically reviewed the manuscript, JLO performed functional studies, xenograft experiments, contributed to data analyses and critically reviewed the manuscript, CJW and JMHR conceived the study, designed the experiments and wrote the manuscript. All authors discussed the results and revised the manuscript.

\section{Compliance with ethical standards}

Conflict of interest CJW is a co-founder of Neon Therapeutics, Inc and is a member of its scientificadvisory board. The remaining authors declare no conflict of interest.

Publisher's note Springer Nature remains neutral with regard to jurisdictional claims in published maps and institutional affiliations.

Open Access This article is licensed under a Creative Commons Attribution 4.0 International License, which permits use, sharing, adaptation, distribution and reproduction in any medium or format, as long as you give appropriate credit to the original author(s) and the source, provide a link to the Creative Commons license, and indicate if changes were made. The images or other third party material in this article are included in the article's Creative Commons license, unless indicated otherwise in a credit line to the material. If material is not included in the article's Creative Commons license and your intended use is not permitted by statutory regulation or exceeds the permitted use, you will need to obtain permission directly from the copyright holder. To view a copy of this license, visit http://creativecommons. org/licenses/by/4.0/.

\section{References}

1. Döhner H, Stilgenbauer S, James MR, Benner A, Weilguni T, Bentz M, et al. 11q deletions identify a new subset of B-cell chronic lymphocytic leukemia characterized by extensive nodal involvement and inferior prognosis. Blood. 1997;89:2516-22.

2. Neilson JR, Auer R, White D, Bienz N, Waters JJ, Whittaker JA, et al. Deletions at $11 \mathrm{q}$ identify a subset of patients with typical CLL who show consistent disease progression and reduced survival. Leukemia. 1997;11:1929-32.

3. Döhner H, Stilgenbauer S, Benner A, Leupolt E, Kröber A, Bullinger L, et al. Genomic aberrations and survival in chronic lymphocytic leukemia. N. Engl J Med. 2000;343:1910-6.

4. Stilgenbauer S, Liebisch P, James MR, Schröder M, Schlegelberger B, Fischer K, et al. Molecular cytogenetic delineation of a novel critical genomic region in chromosome bands 11q22.3923.1 in lymphoproliferative disorders. Proc Natl Acad Sci USA. 1996;93:11837-41. 
5. Gunnarsson R, Mansouri L, Isaksson A, Göransson H, Cahill N, Jansson M, et al. Array-based genomic screening at diagnosis and during follow-up in chronic lymphocytic leukemia. Haematologica 2011;96:1161-9.

6. Rose-Zerilli MJJ, Forster J, Parker H, Parker A, Rodriguez AE, Chaplin T, et al. ATM mutation rather than BIRC3 deletion and/or mutation predicts reduced survival in 11q-deleted chronic lymphocytic leukemia: data from the UK LRF CLL4 trial. Haematologica. 2014;99:736-42.

7. Edelmann J, Holzmann K, Miller F, Winkler D, Bühler A, Zenz T, et al. High-resolution genomic profiling of chronic lymphocytic leukemia reveals new recurrent genomic alterations. Blood. 2012;120:4783-94.

8. Stankovic T, Skowronska A. The role of ATM mutations and 11q deletions in disease progression in chronic lymphocytic leukemia. Leuk Lymphoma. 2014;55:1227-39.

9. Lavin MF. Ataxia-telangiectasia: from a rare disorder to a paradigm for cell signalling and cancer. Nat Rev Mol Cell Biol. 2008;9:759-69.

10. Choi M, Kipps T, Kurzrock R. ATM mutations in cancer: therapeutic implications. Mol Cancer Ther. 2016;15:1781-91.

11. Austen B, Powell JE, Alvi A, Edwards I, Hooper L, Starczynski J, et al. Mutations in the ATM gene lead to impaired overall and treatment-free survival that is independent of IGVH mutation status in patients with B-CLL. Blood. 2005; 106:3175-82.

12. Landau DA, Tausch E, Taylor-Weiner AN, Stewart C, Reiter JG, Bahlo J, et al. Mutations driving CLL and their evolution in progression and relapse. Nature. 2015;526:525-30.

13. Puente XS, Beà S, Valdés-Mas R, Villamor N, Gutiérrez-Abril J, Martín-Subero JI, et al. Non-coding recurrent mutations in chronic lymphocytic leukaemia. Nature. 2015;526:519-24.

14. Austen B, Skowronska A, Baker C, Powell JE, Gardiner A, Oscier $\mathrm{D}$, et al. Mutation status of the residual ATM allele is an important determinant of the cellular response to chemotherapy and survival in patients with chronic lymphocytic leukemia containing an 11q deletion. J Clin Oncol. 2007;25:5448-57.

15. Skowronska A, Parker A, Ahmed G, Oldreive C, Davis Z, Richards S, et al. Biallelic ATM inactivation significantly reduces survival in patients treated on the United Kingdom Leukemia Research Fund Chronic Lymphocytic Leukemia 4 trial. J Clin Oncol. 2012;30:4524-32.

16. Brown JR, Porter DL, O'Brien SM. Novel treatments for chronic lymphocytic leukemia and moving forward. Am Soc Clin Oncol Educ B. 2014;34:e317-25.

17. Barr PM, Robak T, Owen C, Tedeschi A, Bairey O, Bartlett NL, et al. Sustained efficacy and detailed clinical follow-up of first-line ibrutinib treatment in older patients with chronic lymphocytic leukemia: extended phase 3 results from RESONATE-2. Haematologica. 2018;103:1502-10.

18. Kipps TJ, Fraser G, Coutre SE, Brown JR, Barrientos JC, Barr $\mathrm{PM}$, et al. Long-term studies assessing outcomes of ibrutinib therapy in patients with del(11q) chronic lymphocytic leukemia. Clin Lymphoma Myeloma Leuk. 2019;19:715-22.

19. O'Brien S, Furman RR, Coutre S, Flinn IW, Burger JA, Blum K, et al. Single-agent ibrutinib in treatment-naïve and relapsed/ refractory chronic lymphocytic leukemia: a 5-year experience. Blood. 2018;131:1910-9.

20. Woyach JA, Furman RR, Liu T-M, Ozer HG, Zapatka M, Ruppert AS, et al. Resistance mechanisms for the Bruton's tyrosine kinase inhibitor ibrutinib. N. Engl J Med. 2014;370:2286-94.

21. Furman RR, Cheng S, Lu P, Setty M, Perez AR, Guo A, et al. Ibrutinib resistance in chronic lymphocytic leukemia. N. Engl J Med. 2014;370:2352-4.

22. Burger JA, Landau DA, Taylor-Weiner A, Bozic I, Zhang H, Sarosiek $\mathrm{K}$, et al. Clonal evolution in patients with chronic lymphocytic leukaemia developing resistance to BTK inhibition. Nat Commun. 2016;7:11589.

23. Landau DA, Sun C, Rosebrock D, Herman SEM, Fein J, Sivina $\mathrm{M}$, et al. The evolutionary landscape of chronic lymphocytic leukemia treated with ibrutinib targeted therapy. Nat Commun. 2017;8:2185

24. Ahn IE, Underbayev C, Albitar A, Herman SEM, Tian X, Maric I, et al. Clonal evolution leading to ibrutinib resistance in chronic lymphocytic leukemia. Blood. 2017;129:1469-79.

25. Rodríguez D, Bretones G, Quesada V, Villamor N, Arango JR, López-Guillermo A, et al. Mutations in CHD2 cause defective association with active chromatin in chronic lymphocytic leukemia. Blood. 2015;126:195-202.

26. Zenz T, Häbe S, Denzel T, Mohr J, Winkler D, Bühler A, et al. Detailed analysis of p53 pathway defects in fludarabine-refractory chronic lymphocytic leukemia (CLL): dissecting the contribution of $17 \mathrm{p}$ deletion, TP53 mutation, p53-p21 dysfunction, and miR34a in a prospective clinical trial. Blood. 2009;114:2589-97.

27. Navrkalova V, Sebejova L, Zemanova J, Kminkova J, Kubesova B, Malcikova J, et al. ATM mutations uniformly lead to ATM dysfunction in chronic lymphocytic leukemia: application of functional test using doxorubicin. Haematologica. 2013;98:1124-31.

28. Arruga F, Gizdic B, Bologna C, Cignetto S, Buonincontri R, Serra $\mathrm{S}$, et al. Mutations in NOTCH1 PEST domain orchestrate CCL19driven homing of chronic lymphocytic leukemia cells by modulating the tumor suppressor gene DUSP22. Leukemia. 2017;31:1882-93.

29. Close V, Close W, Kugler SJ, Reichenzeller M, Yosifov DY, Bloehdorn $\mathrm{J}$, et al. FBXW7 mutations reduce binding of NOTCH1, leading to cleaved NOTCH1 accumulation and target gene activation in CLL. Blood. 2019;133:830-9.

30. Yin S, Gambe RG, Sun J, Martinez AZ, Cartun ZJ, Regis FFD, et al. A murine model of chronic lymphocytic leukemia based on B cell-restricted expression of Sf3b1 mutation and Atm deletion. Cancer Cell. 2019;35:283-296.e5.

31. Cong L, Ran FA, Cox D, Lin S, Barretto R, Habib N, et al. Multiplex genome engineering using CRISPR/Cas systems. Science. 2013;339:819-23.

32. Hsu PD, Lander ES, Zhang F. Development and applications of CRISPR-Cas9 for genome engineering. Cell. 2014;157:1262-78.

33. Canver MC, Bauer DE, Dass A, Yien YY, Chung J, Masuda T, et al. Characterization of genomic deletion efficiency mediated by clustered regularly interspaced palindromic repeats (CRISPR)/ Cas9 nuclease system in mammalian cells. J Biol Chem. 2014;289:21312-24.

34. Essletzbichler P, Konopka T, Santoro F, Chen D, Gapp BV, Kralovics R, et al. Megabase-scale deletion using CRISPR/Cas9 to generate a fully haploid human cell line. Genome Res. 2014;24:2059-65.

35. García-Tuñón I, Hernández-Sánchez M, Ordoñez JL, AlonsoPérez V, Álamo-Quijada $\mathrm{M}$, Benito $\mathrm{R}$, et al. The CRISPR/ Cas9 system efficiently reverts the tumorigenic ability of BCR/ $\mathrm{ABL}$ in vitro and in a xenograft model of chronic myeloid leukemia. Oncotarget. 2017;8:26027-40.

36. Purroy N, Abrisqueta P, Carabia J, Carpio C, Calpe E, Palacio C, et al. Targeting the proliferative and chemoresistant compartment in chronic lymphocytic leukemia by inhibiting survivin protein. Leukemia. 2014;28:1993-2004.

37. Primo D, Scarfò L, Xochelli A, Mattsson M, Ranghetti P, Espinosa $\mathrm{AB}$, et al. A novel ex vivo high-throughput assay reveals antiproliferative effects of idelalisib and ibrutinib in chronic lymphocytic leukemia. Oncotarget. 2018;9:26019-31.

38. Knittel G, Liedgens P, Reinhardt HC. Targeting ATM-deficient CLL through interference with DNA repair pathways. Front Genet. 2015;6:207. 
39. Scaffidi P, Misteli T, Bianchi ME. Release of chromatin protein HMGB 1 by necrotic cells triggers inflammation. Nature. 2002;418:191-5.

40. Guo A, Lu P, Galanina N, Nabhan C, Smith SM, Coleman M, et al. Heightened BTK-dependent cell proliferation in unmutated chronic lymphocytic leukemia confers increased sensitivity to ibrutinib. Oncotarget. 2016;7:4598-610.

41. te Raa GD, Derks IAM, Navrkalova V, Skowronska A, Moerland PD, van Laar J, et al. The impact of SF3B1 mutations in CLL on the DNA-damage response. Leukemia. 2015;29:1133-42.

42. Mao Z, Bozzella M, Seluanov A, Gorbunova V. Comparison of nonhomologous end joining and homologous recombination in human cells. DNA Repair (Amst). 2008;7:1765-71.

43. Seluanov A, Mao Z, Gorbunova V. Analysis of DNA doublestrand break (DSB) repair in mammalian cells. J Vis Exp. 2010; e2002.

44. Landau DA, Carter SL, Stojanov P, McKenna A, Stevenson K, Lawrence MS, et al. Evolution and impact of subclonal mutations in chronic lymphocytic leukemia. Cell. 2013;152:714-26.

45. Wang L, Fan J, Francis JM, Georghiou G, Hergert S, Li S, et al. Integrated single-cell genetic and transcriptional analysis suggests novel drivers of chronic lymphocytic leukemia. Genome Res. 2017;27:1300-11.

46. Burma S, Chen BP, Murphy M, Kurimasa A, Chen DJ. ATM phosphorylates histone $\mathrm{H} 2 \mathrm{AX}$ in response to DNA double-strand breaks. J Biol Chem. 2001;276:42462-7.

47. Ouillette P, Fossum S, Parkin B, Ding L, Bockenstedt P, Al-Zoubi A, et al. Aggressive chronic lymphocytic leukemia with elevated genomic complexity is associated with multiple gene defects in the response to DNA double-strand breaks. Clin Cancer Res. 2010;16:835-47.

48. Hernández JÁ, Hernández-Sánchez M, Rodríguez-Vicente AE, Grossmann V, Collado R, Heras C, et al. A low frequency of losses in 11q chromosome is associated with better outcome and lower rate of genomic mutations in patients with chronic lymphocytic leukemia. PLoS ONE. 2015;10:e0143073.

49. Bakhoum SF, Landau DA. Chromosomal instability as a driver of tumor heterogeneity and evolution. Cold Spring Harb Perspect Med. 2017;7:a029611.

50. Puiggros A, Collado R, Calasanz MJ, Ortega M, Ruiz-Xivillé N, Rivas-Delgado A, et al. Patients with chronic lymphocytic leukemia and complex karyotype show an adverse outcome even in absence of TP53/ATM FISH deletions. Oncotarget. 2017;8:54297-303.

51. Thompson PA, O'Brien SM, Wierda WG, Ferrajoli A, Stingo F, Smith SC, et al. Complex karyotype is a stronger predictor than $\operatorname{del}(17 p)$ for an inferior outcome in relapsed or refractory chronic lymphocytic leukemia patients treated with ibrutinib-based regimens. Cancer. 2015;121:3612-21.

52. Weston VJ, Oldreive CE, Skowronska A, Oscier DG, Pratt G, Dyer MJS, et al. The PARP inhibitor olaparib induces significant killing of ATM-deficient lymphoid tumor cells in vitro and in vivo. Blood. 2010;116:4578-87.

53. Knittel G, Rehkämper T, Korovkina D, Liedgens P, Fritz C, Torgovnick A, et al. Two mouse models reveal an actionable PARP1 dependence in aggressive chronic lymphocytic leukemia. Nat Commun. 2017;8:153.

54. Byrd JC, Brown JR, O’Brien S, Barrientos JC, Kay NE, Reddy $\mathrm{NM}$, et al. Ibrutinib versus Ofatumumab in previously treated chronic lymphoid leukemia. N. Engl J Med. 2014;371:213-23.

55. Juvekar A, Burga LN, Hu H, Lunsford EP, Ibrahim YH, Balmañà J, et al. Combining a PI3K inhibitor with a PARP inhibitor provides an effective therapy for BRCA1-related breast cancer. Cancer Disco. 2012;2:1048-63.

56. Kwok M, Davies N, Agathanggelou A, Smith E, Oldreive C, Petermann E, et al. ATR inhibition induces synthetic lethality and overcomes chemoresistance in TP53- or ATM-defective chronic lymphocytic leukemia cells. Blood. 2016;127:582-95.

57. Compagno M, Wang Q, Pighi C, Cheong T-C, Meng F-L, Poggio $\mathrm{T}$, et al. Phosphatidylinositol 3-kinase $\delta$ blockade increases genomic instability in B cells. Nature. 2017;542:489-93.

58. Chanan-Khan A, Cramer P, Demirkan F, Fraser G, Silva RS, Grosicki S, et al. Ibrutinib combined with bendamustine and rituximab compared with placebo, bendamustine, and rituximab for previously treated chronic lymphocytic leukaemia or small lymphocytic lymphoma (HELIOS): a randomised, double-blind, phase 3 study. Lancet Oncol. 2016;17:200-11.

59. Robson M, Im S-A, Senkus E, Xu B, Domchek SM, Masuda N, et al. Olaparib for metastatic breast cancer in patients with a germline BRCA mutation. N. Engl J Med. 2017;377:523-33.

60. Pujade-Lauraine E, Ledermann JA, Selle F, Gebski V, Penson RT, Oza AM, et al. Olaparib tablets as maintenance therapy in patients with platinum-sensitive, relapsed ovarian cancer and a BRCA1/2 mutation (SOLO2/ENGOT-Ov21): a double-blind, randomised, placebo-controlled, phase 3 trial. Lancet Oncol. 2017;18:1274-84. 